\title{
Study on Properties of Silver Powder for Maki-e
}

\author{
Chieko Narita1, Yutaro Shimode ${ }^{2}$, Kazushi Yamada ${ }^{*}$ \\ ${ }^{1}$ Department of Advanced Fibro-Science, Kyoto Institute of Technology, Kyoto, Japan \\ ${ }^{2}$ Future Applied Conventional Technology Center, Kyoto Institute of Technology, Kyoto, Japan \\ Email: ${ }^{*}$ kazushi@kit.ac.jp
}

Received 27 October 2014; revised 20 November 2014; accepted 10 December 2014

Copyright (C) 2015 by authors and Scientific Research Publishing Inc.

This work is licensed under the Creative Commons Attribution International License (CC BY).

http://creativecommons.org/licenses/by/4.0/

(c) (i) Open Access

\begin{abstract}
Maki-e is a traditional Japanese decorative technique that uses the natural lacquer Urushi and metal powders. In 2014 , there exist only two companies that manufacture silver powder for the purpose of Maki-e, and this study focuses on comparing the powders manufactured by them. Gloss and color of each silver powder were measured after Maki-e decoration was finished, and EDS (energy-dispersive X-ray spectroscopy) was used to determine the differences in their chemical composition. In addition, to verify the effect of polishing, residual gloss after sulfuration and polishing was measured. The study revealed that the shapes of the silver powders (Maru-fun, No. 1) manufactured by the two companies are different and it affects the occupancy rate of Urushi and powder, which in turn affects their gloss and color. Wakou silver has a very strong resistance to sulfuration; however, owing to its Pd content, its chroma is much lower than that of other powders. It was shown that sulfuration on powder surface can be removed by polishing irrespective of the shape and chemical composition ratio of the particles.
\end{abstract}

\section{Keywords}

Urushi, Natural Lacquer, Maki-e, Silver Powder, Energy-Dispersive X-Ray Spectroscopy

\section{Introduction}

Lacquer craft is a typical traditional craft of Japan. Maki-e is a drawing technique that uses the natural lacquer Urushi and metal powders. It is a decorative technique that was developed originally in Japan; however, other Southeast Asian countries, such as Korea and China, also have similar style and techniques for lacquer craft [1] [2].

*Corresponding author. 
While several studies concerning Urushi have been conducted all over the world [3]-[6], very few focused on Maki-e. Only the names of notable artists and their works appear on studies that report on artwork and its collection [7]-[9]. There are, however, a few investigations that focus on the conservation of Maki-e works and the Maki-e technique; these studies did not use real materials though [10]. There are also some studies regarding the techniques and powders used in the past in Japan [11]-[13]. However, to the best of our knowledge, metal powders that are presently used in Maki-e have never been investigated.

In 2014, only two companies manufacture metal powders for Maki-e. Artists claim that the appearance of a Maki-e is different if it is drawn using the same kind of powder from the two different companies. In fact, even if the name of the powder produced by the two companies is the same, the shapes of the powder particles are different [14]. However, the details of the shapes have never been fully characterized. The metals commonly employed for the production of Maki-e powders include gold, silver, gold-silver alloys, copper, and tin. Silver powder tarnishes with age because of the reaction with atmospheric sulfur, while gold powder is less reactive, thus more stable in time. Occasionally, Maki-e artworks are polished to restore the original gloss of the sulfurized silver powder.

This research compares the silver powders manufactured by the two companies. Gloss, color, and shape were measured before and after drawing some Maki-e decorations to characterize each powder and the consequent appearance of the Maki-e decorations in detail. In addition, the effect of polishing for different kinds of silver powder was examined.

\section{Experimental}

\subsection{Samples}

Silver Maru-fun, which is a powder made of silver round particles, was used for the comparison. One company produces 15 kinds of Maru-fun, while the other manufactures 30 kinds. The smallest powder is named No. 1, and the number increases as the diameter of the powder particles increases. According to an interview with Maki-e craftsmen, they usually use powders from No. 1 to No. 15, with No. 1 being the most used. Hence, No. 1 powder produced by both Asano Co., Ltd. (sample A) and Yoshii Co., Ltd. (sample B) was studied and compared with Wakou silver powder by Yoshii Co., Ltd. (sample C). Wakou silver powders are said to be more resistant to sulfuration than other silver powder.

Acrylic boards of the size $100 \times 50 \times 5 \mathrm{~mm}^{3}$ were used as substrates to create Maki-e. Silver powder was sprinkled on $80 \times 50 \mathrm{~mm}^{2}$ of the board surface. The powder was sprinkled densely to the maximum by the Tume-maki technique. E-Urushi, which is mixture of Suke-Urushi (reined Urushi with high transparency) and red oxide, was used to draw Maki-e pattern and bond Maki-e powder to the board. Sample preparation is schematized in Figure 1.

Sample A and B were both white in color, while Wakou silver powder was dark gray (Figure 2). The appearance of the samples is shown in Figure 3.
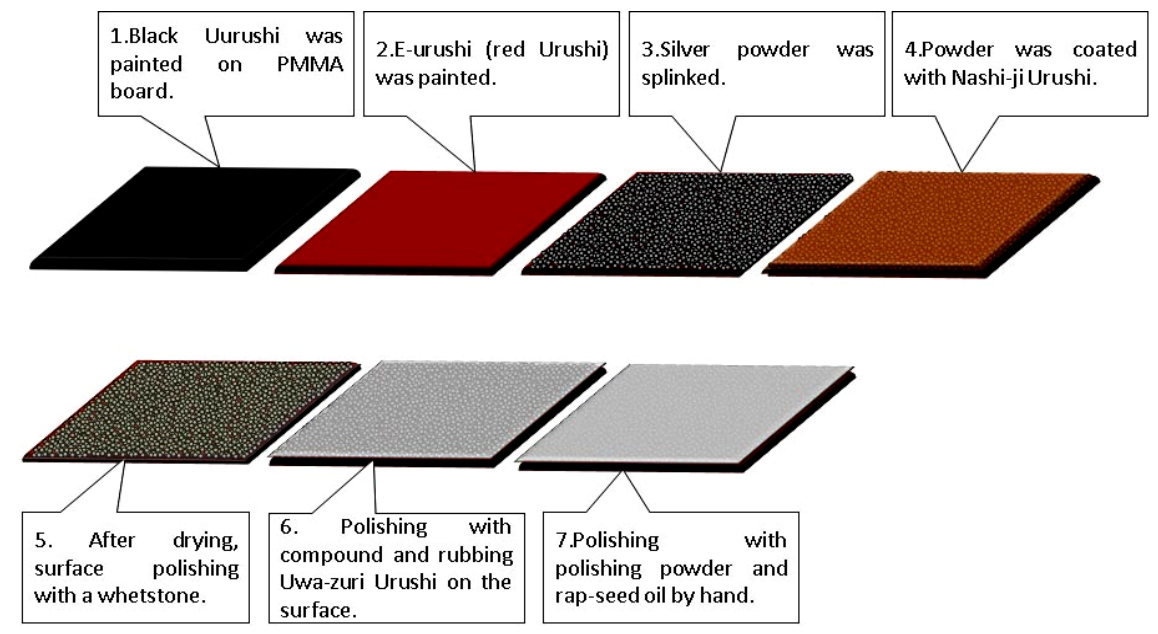

Figure 1. Scheme of sample preparation. 


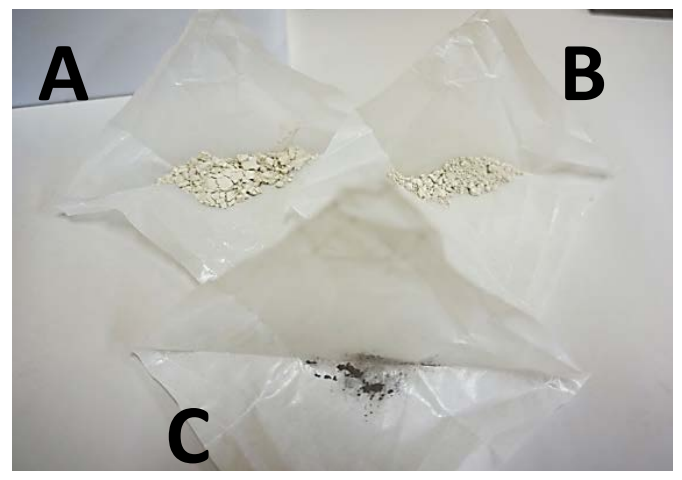

Figure 2. Photo of each powder before Maki-e decoration.

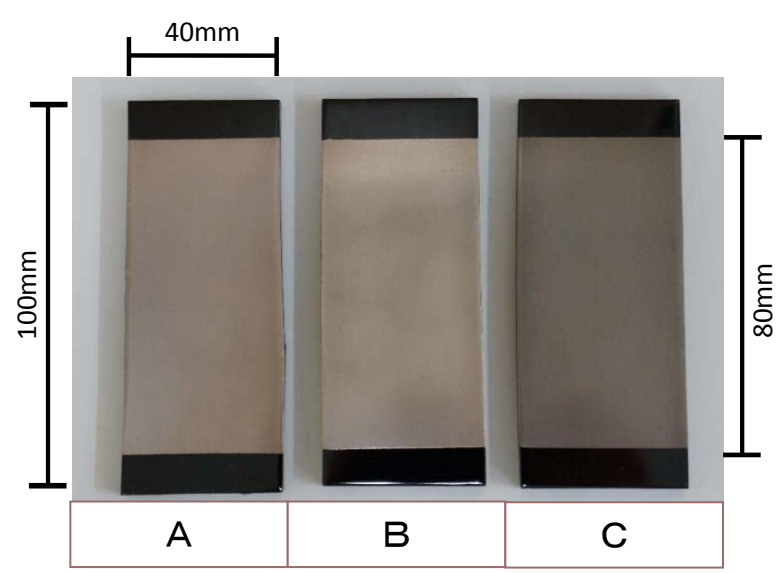

Figure 3. Photo of each sample.

\subsection{Measurement Methods}

\subsubsection{Gloss and Color Measurements}

A glossmeter (IG-410, HORIBA, Ltd.) was used to measure the gloss and the measurement scale was calibrated from 0 to 1000 gloss units. The measurement angle was 60 degrees.

Color was measured by analyzing sample pictures taken using a single lens reflex camera (NEX-7, SONY Co., Ltd.) with IGOR Pro (6.34 A, Wave Metrics, Inc.). The results of the measurements were expressed in the $\mathrm{L}^{*} \mathrm{a}^{*}$ $\mathrm{b}^{*}$, or CIELab, color space, which is an international standard adopted by the Commission Internationaled' Eclairage (CIE) in 1976 for color measurements. $\mathrm{L}^{*}$ is the luminance or lightness component, which ranges from 0 to 100, and parameters $\mathrm{a}^{*}$ (from green to red) and $\mathrm{b}^{*}$ (from blue to yellow) are the two chromatic components, which range from -120 to 120 . $\mathrm{C}^{*}$, which is calculated from $\mathrm{a}^{*}$ and $\mathrm{b}^{*}$, corresponds to the chroma.

\subsubsection{Observation of Sample Surface}

A laser microscope (VK-X100, KEYENCE Co., Ltd.) was used for surface observation at 100× magnification. IGOR Pro was used to calculate the occupancy rates of the sample powders.

\subsubsection{EDS Analysis}

EDS analysis of the surface of the powders was performed using a system coupled with a scanning electron microscope (JSM-6010LA, JOEL Ltd.). EDS identifies elements in a sample by detecting characteristic X-rays emitted by the sample surface after interaction with an impinging electron beam. EDS can detect elements in the periodic table from boron to uranium.

\subsection{Sulfuration Test and Polishing Method}

All sample surfaces were immersed in a dilute solution of hydrogen sulfide to accelerate silver sulfuration [15]. 
The Maki-e were polished by the traditional method for polishing, which is to polish the surface by hand with a polishing powder called Roiro-ko and rape-seed oil. To verify the effectiveness of the polishing procedure, residual gloss after the sulfuration test and polishing was calculated with respect to the gloss of the untreated surface with the following equation:

Residual gloss $(\%)=(($ Gloss after sulfuration test or after polishing $) /$ Gloss before test $) \times 100 \quad$ [16]

\section{Results and Discussions}

\subsection{Gloss and Color Measurements}

Figure 4 compares the gloss of the samples, and Figure 5 compares their color coordinates. Sample B had the highest gloss, followed by A and C in decreasing order; A had the highest value of $\mathrm{C}^{*}$, followed by $\mathrm{B}$ and $\mathrm{C}$ in decreasing order; and $\mathrm{B}$ had the highest $\mathrm{L}^{*}$ value, followed by $\mathrm{C}$ and $\mathrm{A}$ in decreasing order.

Sample A had moderate gloss and the highest $\mathrm{C}^{*}$ value, however $\mathrm{L}^{*}$ value was the lowest. Sample B had the highest gloss and $\mathrm{L}^{*}$ value, and moderate $\mathrm{C}^{*}$ value. Sample $\mathrm{C}$ had the highest gloss and the lowest $\mathrm{C}^{*}$.

The lower $\mathrm{C}^{*}$ of sample $\mathrm{C}$ is due to the dark gray color of the powder used for this Maki-e. Besides, the difference in A and B about appearance was shown numerically as it has been pointed out which was mentioned in introduction. The surfaces of the samples were observed to examine how the silver particle shape affects the final appearance of the Maki-e.

\subsection{Surface Observation}

The surfaces of the samples were observed to clarify whether gloss and color depend on the powder properties or on the decorating process of Maki-e. Photomicrographs of sample surfaces are shown in Figure 6. Both average and distribution of the particle size were smaller for sample A compared to those of samples B and C. On the contrary, the powder used for samples B and C had a wider particle size distribution.

Surface texture, given by the amount of powder on the surface, was measured through the calculation of the powder occupancy rate per substrate unit area by binary coded processing (IGOR Pro 6.34A) of Figure 6. Occupancy rate of powder per unit area was $20.5 \%$ for sample A, $30.5 \%$ for sample B, and $23.0 \%$ for sample C.
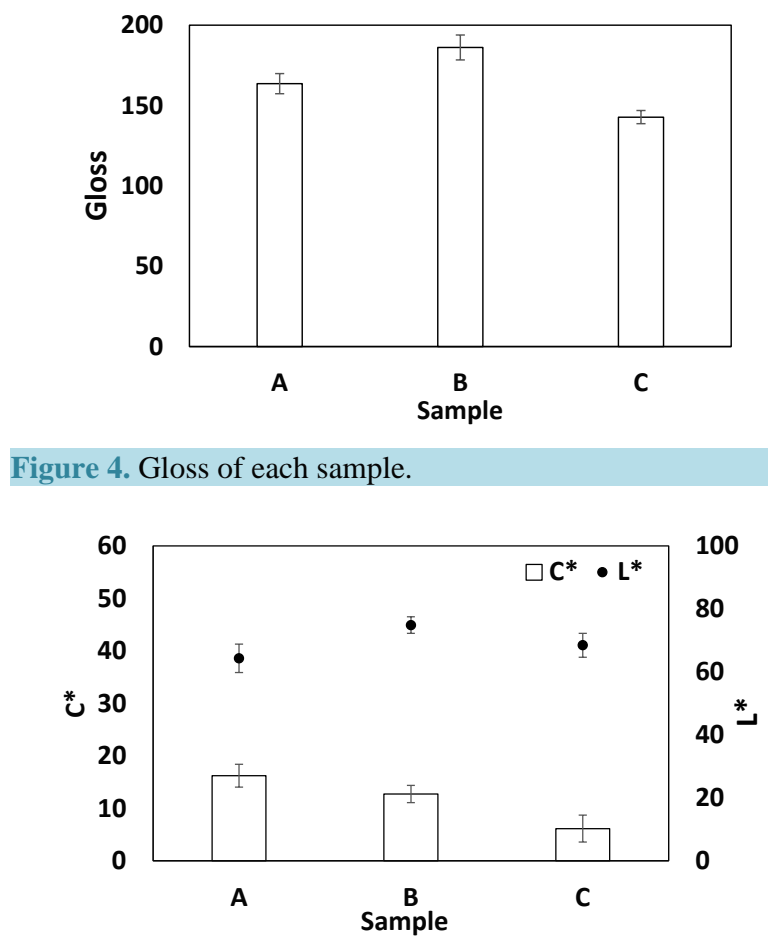

Figure 5. L* and C* values of each sample. 
This indicated that the occupancy rate decreased with decreasing particle size if it was relatively less uneven. Therefore, it is demonstrated that particle size and particle size distribution affect the appearance of the Maki-e. However, it was unclear whether the original elemental composition of the powder or the processing method of the powder that affected the particle shapes.

\subsection{EDS Analysis}

Figure 7 provides the EDS spectra for the samples and Figure 8 shows relative element concentrations.

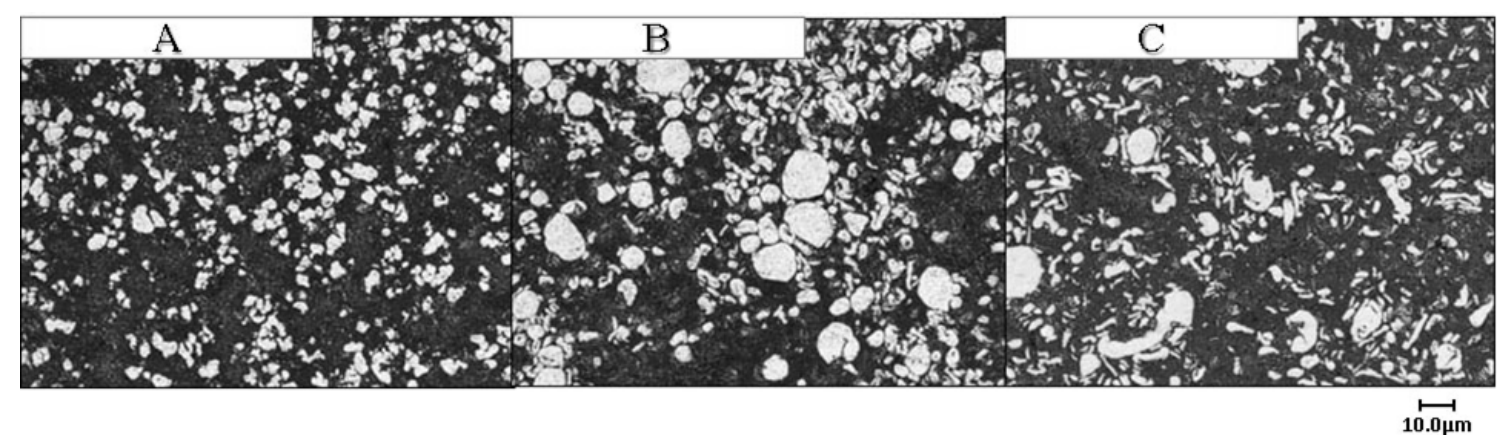

Figure 6. Sample photomicrographs acquired by laser microscopy at 100× magnification.

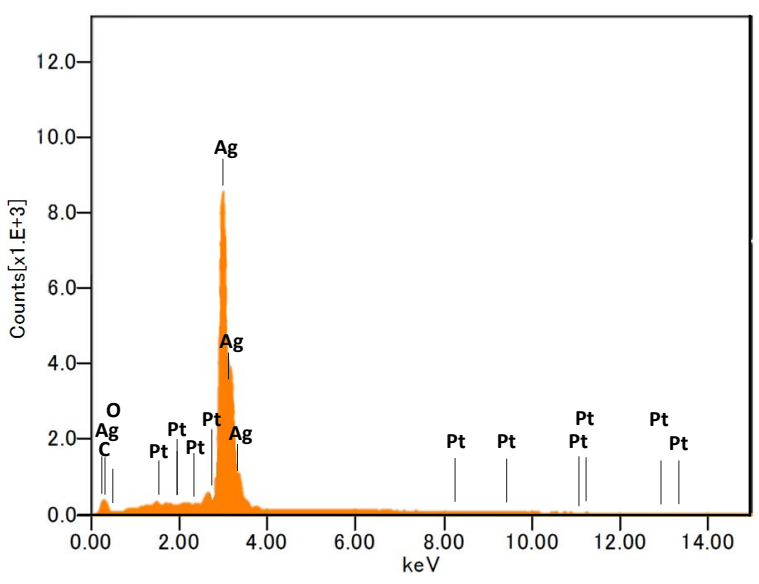

(a)

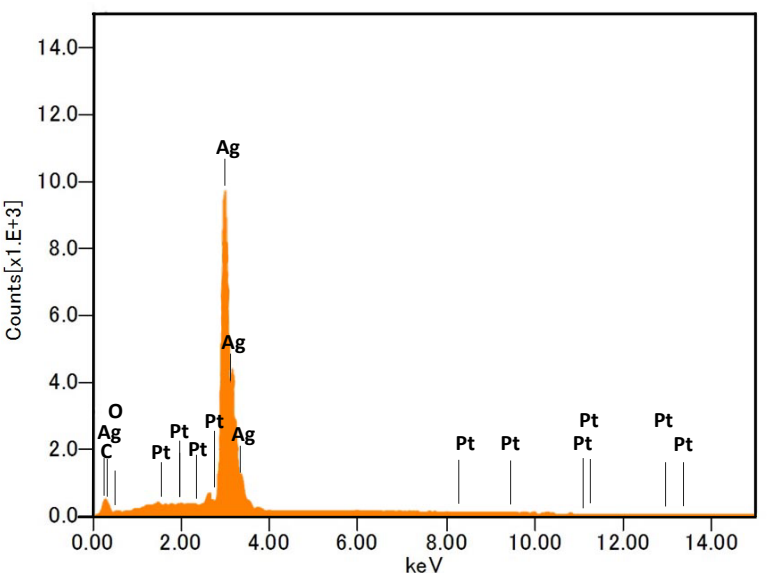

(b)

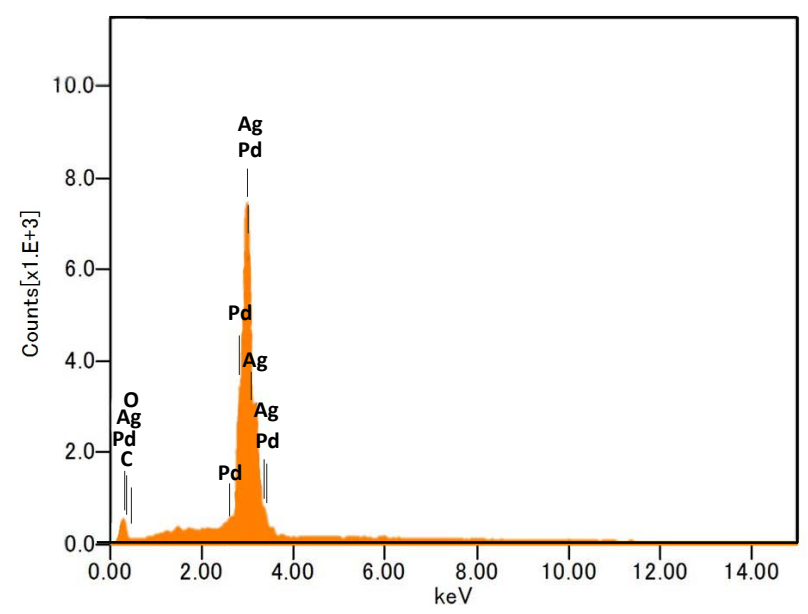

(b)

Figure 7. EDS spectra of (a) Sample A; (b) Sample B; (c) Sample C. 
Samples A and B were made of ca. 95\% Ag, while sample C was made of ca. $70 \%$ Ag and of ca. $18 \%$ Pd. Oxygen and carbon were the main other elements present in all the three powders, probably as a result of deposition on powder surface. Trace amounts of Pt were detected only in samples A and B; however, this may be inadvertently included during the metal refining process. As the powder components were almost the same, it seems that the gloss and color are not affected by powder chemistry with the exception of sample $\mathrm{C}$ whose powder color is attributable to the presence of Pd.

Hence, it can be concluded that the gloss and color of the samples depend on the particle shape and occupancy rate. Shimode et al. reported that occupancy rate decreases with decreasing particle size in a study of Eggshell Maki-e, which is a type of Maki-e powder that is made of finely crushed egg shells. They also reported that the powder occupancy rate affects the appearance of Maki-e [17]. Low particle occupancy rate implies that the occupancy rate of Urushi becomes larger. This is the reason why $\mathrm{C}^{*}$ value of sample A, with lower particle occupancy rate, was higher than that of the other samples which are less affected by the deep red color of E-Urushi. Furthermore, sample B has a higher powder occupancy rate than sample A, which may have resulted in higher gloss.

Therefore, the differences in the gloss and color of the appearance of samples after Maki-e decoration are due to the effect of occupancy rate and the differences in particle shape. Despite the occupancy rate of sample C being larger than that of A, C had the lowest gloss among all the samples. This may be attributed to the original gloss of the $\mathrm{C}$ powder and not its occupancy rate.

\subsection{Variation of Residual Gloss by Polishing}

The photomicrographs of the surface of the samples after sulfuration are shown in Figure 9. The residual gloss after sulfuration and polishing is shown in Table 1. The gloss of samples A and B after sulfuration decreased by ca. $50 \%$ with respect to the gloss before, while the gloss of sample $\mathrm{C}$ decreased only by $10 \%$. A sulfurized film was formed on the surface of samples A and B (Figure 9), but not on sample C. It is likely that the Pd in sample $\mathrm{C}$ played a pivotal role in the prevention of silver sulfuration. For example, a gold-silver-palladium alloy, of the composition $12 \% \mathrm{Au}, 50 \% \mathrm{Ag}$, and $20 \% \mathrm{Pd}$, is used as metal crown for dental treatment; in this case, Pd is included to prevent discoloration after sulfuration of Ag [18].

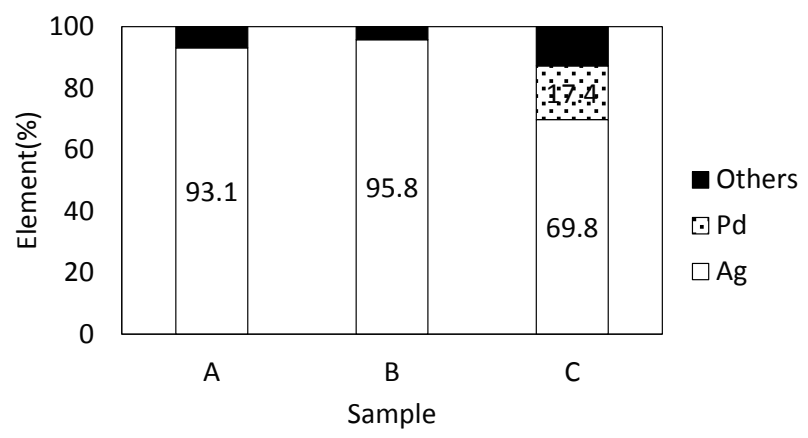

Figure 8. Relative element concentrations in the samples calculated from EDS data.

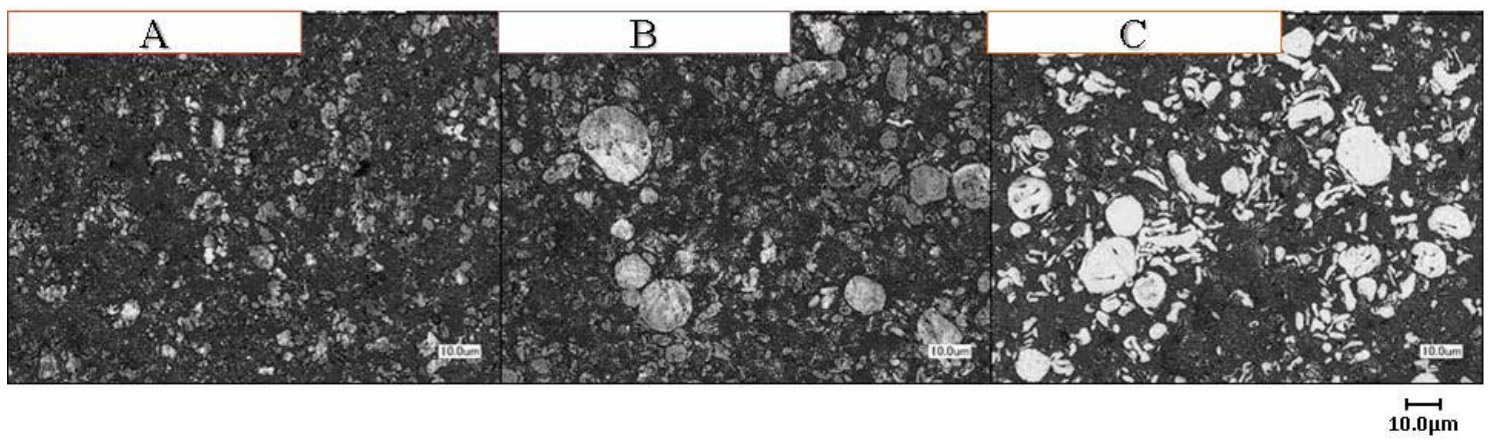

Figure 9. Sample photomicrographs after sulfurization acquired by laser microscopy at 100× magnification. 
Table 1. Residual gloss (\%) of each sample after sulfuration and after polishing with respect to gloss of the untreated surface.

\begin{tabular}{cccc}
\hline \multicolumn{1}{c}{ Sample } & A & B & C \\
\hline Condition & 56.4 & 42.1 & 91.4 \\
After sulfuration & 98.1 & 99.6 & 100.9 \\
\hline After polishing & & \\
\hline
\end{tabular}

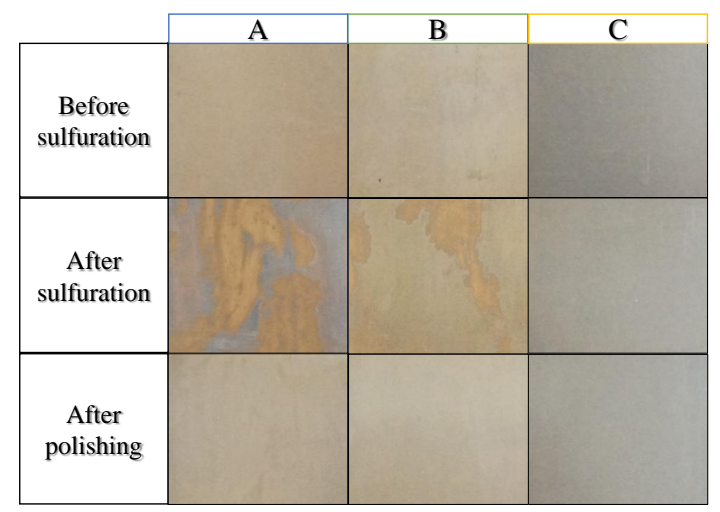

Figure 10. Photos of each sample before and after sulfuration and polishing.

The appearance of the samples before and after sulfuration, and after polishing is shown in Figure 10. By polishing the sample after sulfuration, the gloss of all the samples, irrespective of the shape and chemistry of the silver powder particles, increased by almost $100 \%$, and the particles appeared the same as they did before sulfuration. This implies that polishing removes the film that was formed during sulfuration.

The craftsman who polished the samples was interviewed to obtain information on the ease of the polishing procedure for the different samples. He said that sample B required more time for polishing, while sample $\mathrm{C}$ was easily returned to its original condition. It is hypothesized that the gloss of sample B decreased the most and polishing of this sample took longer because of its higher occupancy rate. The powder used in sample $C$ had stronger resistance to sulfuration than the other two powders, remedying to a defect of silver powder which has been considered to be a problem in the past. However, the expression of each powder is different and it is important to know when to use what type of powder.

\section{Conclusion}

In this research, we characterized silver powders used in Maki-e before and after the decoration. It was demonstrated that the different occupancy rate of different Maru-fun No. 1 silver powders manufactured by two different companies affects the gloss and color of the final artwork. Wakou silver has a very strong resistance to sulfuration; however, owing to its Pd content, its chroma is much lower than that of other powders. Finally, it was shown that polishing effectively removes sulfuration on powder surfaces no matter their shape and elemental composition.

\section{Acknowledgements}

The authors wish to thank sincerely Prof. H. Hamada of the Kyoto Institute of Technology for his contribution to this research. The authors express their gratitude to the members of Shimode Maki-e studio for their kind supply of samples for this study.

The research was financially supported by the Sasakawa Scientific Research Grant from The Japan Science Society (Grant Number 26-142).

\section{References}

[1] Kopplin, M., Ed. (2002) Lacquerware in Asia, Today and Yesterday. United Nations Educational, 19-58. 
[2] Kyoto National Museum, Ed. (2008) Export Lacquer: Reflection of the West in Black and Gold Maki-e Exhibition. The Yomiuri Shimbun, Osaka.

[3] Xiaa, J., Xu, Y., Lina, J. and Hu, B. (2008) UV-Induced Polymerization of Urushiol without Photoinitiator. Progress in Organic Coatings, 61, 7-10. http://dx.doi.org/10.1016/j.porgcoat.2007.08.007

[4] Lee, B.H. and Kim, H.J. (2004) Curing Behaviors of Korean Dendropanax Lacquer Determined by Chemical and Physical Measures. Journal of Applied Polymer Science, 92, 625-630. http://dx.doi.org/10.1002/app.20094

[5] Vogl, O. (2000) Oriental Lacquer, Poison Ivy, and Drying Oils. Journal of Polymer Science Part A: Polymer Chemistry, 38, 4327-4335. http://dx.doi.org/10.1002/1099-0518(20001215)38:24<4327::AID-POLA10>3.0.CO;2-3

[6] Nairta, C., Endo, A., Shimode, Y. and Yamada, K. (2014) Study on the Appearance Characteristics and Peel Strength of Byakudannuri. Materials Sciences and Applications, 5, 81-85. http://dx.doi.org/10.4236/msa.2014.52012

[7] Canepa, T. (2009) Namban Lacquer for the Portuguese and Spanish Missionaries. Bulletin of Portuguese-Japanese Studies, 18-19, 253-290.

[8] Bincsik, M. (2008) European Collectors and Japanese Merchants of Lacquer in “Old Japan”. Journal of the History of Collection, 20, 217-236. http://dx.doi.org/10.4236/msa.2014.52012

[9] Covaci, I.A. (2007) Japanese Lacquer in the Yale University Art Gallery Collection: “Nobleman’s Meal Table” and “Kōdaiji Maki-e Trousseau Box”. Yale University Art Gallery Bulletin, 133-137.

[10] Webb, M. (1998) Methods and Materials for Filling Losses on Lacquer Objects. Journal of the American Institute for Conservation, 37, 117-133. http://dx.doi.org/10.1179/019713698806082930

[11] Uchida, T. (2012) Korin Maki-e No Kenkyu. Chuokouronbijyutsu, Tokyo. (In Japanese)

[12] Murose, T. (2009) A Study on Yatsuhashi Maki-e Ink Stone Box: National Treasure. Journal of Cultural Properties, 7 , 33-38.

[13] Nakasato, T. (1972) Study of Metal Particles Used in Ancient Lacquer Arts. Science for Conservation, 9, 63-98.

[14] Gakkai, S., Ed. (2012) Shitsugeijiten. Kadokawa Co., Ltd., Tokyo.

[15] Kato, H., Sano, C., Saito, T. and Uchibori, G. (2004) Coloring Finish of Metal Surface Following Some Traditional Methods-Coloring of Silver and Its Effect. Science for Conservation, 43, 1-8.

[16] Kamiya, Y. and Nishimura, S. (2013) Basic Study on Issue of Change of Color of the Black Lacquer Film-Surface Change Due to the Ultraviolet Irradiation of the Reacted Black Lacquer with Iron. Bulletin of TIRI, 8, 88-91.

[17] Shimode, Y., Nairta, C., Endo, A. and Yamada, K. (2013) Effect of Different Eggshell Powder on Appearance of Eggshell Maki-e. Materials Sciences and Applications, 4, 138-144. http://dx.doi.org/10.4236/msa.2013.42016

[18] Umeda, H., Sasaki, A., Takahashi, K., Haga, K., Takasaki, Y., Kuzuno, E. and Shibayama, A. (2011) Flotation and Process Design for Precious Metals Recovery from Powdery Waste Generated by Polishing Process of Dental Alloy. Journal of MMIJ, 127, 649-655. 
Scientific Research Publishing (SCIRP) is one of the largest Open Access journal publishers. It is currently publishing more than 200 open access, online, peer-reviewed journals covering a wide range of academic disciplines. SCIRP serves the worldwide academic communities and contributes to the progress and application of science with its publication.

Other selected journals from SCIRP are listed as below. Submit your manuscript to us via either submit@scirp.org or Online Submission Portal.
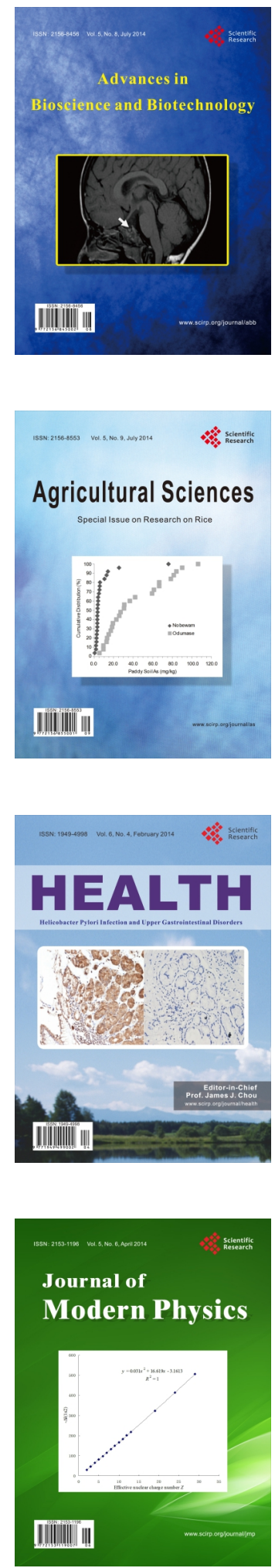
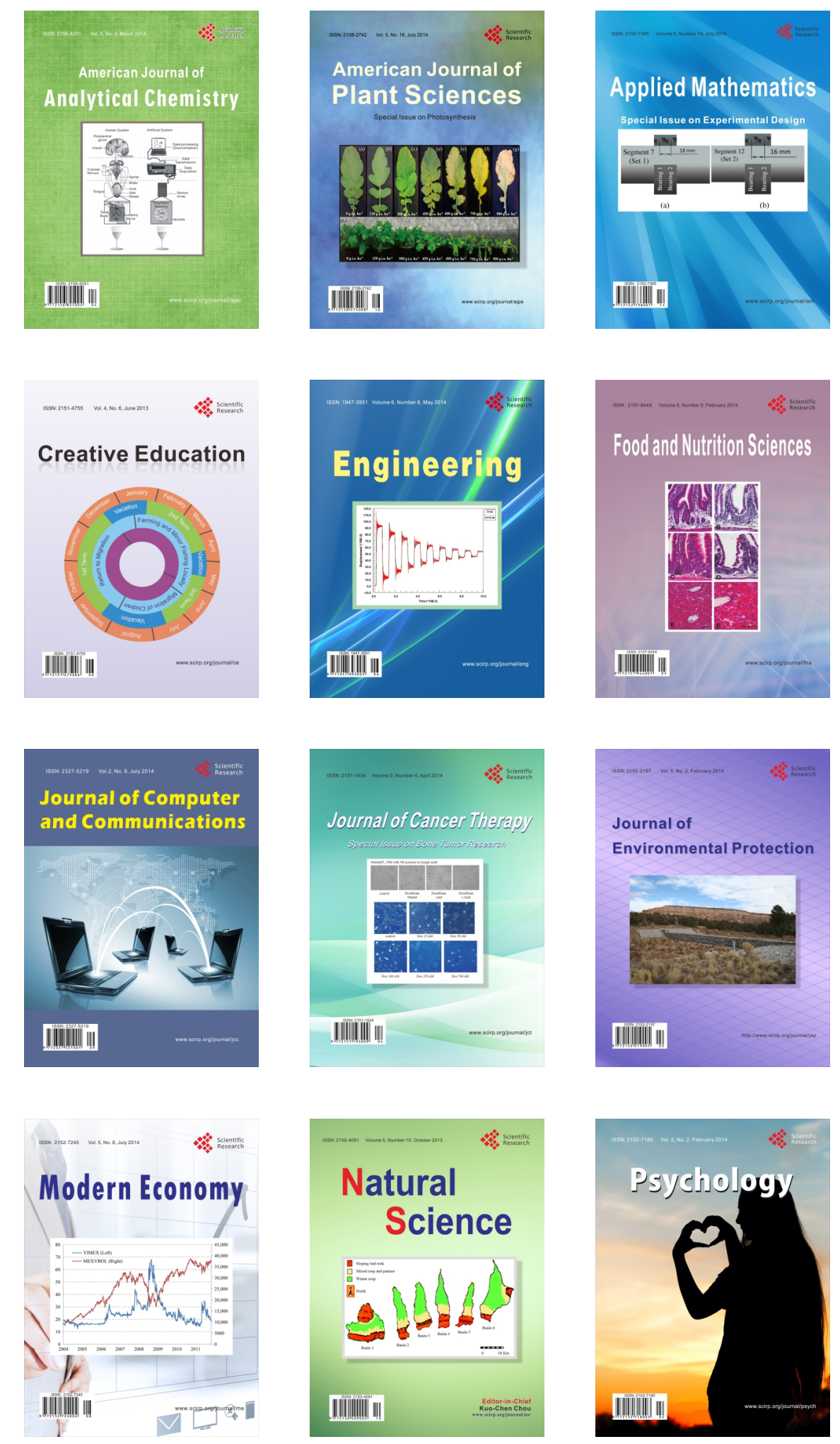